\section{The changing role of Sport \& Exercise Medicine in the post COVID-19 world}

\author{
Polly Baker, ${ }^{1,2}$ Robin Chatterjee (i) ${ }^{3}$
}

COVID-19 has affected all walks of life and posed challenges that one would never have expected. The British Association of Sport \& Exercise Medicine (BASEM), like other organisations, has had to reflect, transform and adapt in response to the global pandemic. For a start, the annual conference scheduled for last November was postponed until this year, but as the UK takes its first tentative steps out of the lockdown, it has now been further postponed to a future date to be confirmed. BASEM has proven to still be able to provide top class education, however, by ways of webinars, by increasing the amount of online material available and by holding its first ever online Spring Conference on 28 May 2021. This 'Hip \& Groin Vision Day' will feature internationally renowned speakers: Per Holmich, Adam Weir, Kristian Thorborg and Andrea Mosler.

BASEM has a varied multidisciplinary membership that works in different settings such as elite sport, primary care and research. Each sector has had its own challenges. This issue of the BJSM aims to reflect the evolving nature of the work being undertaken, clinical issues being faced and direction healthcare is heading.

Included in this issue is an original research piece entitled 'SARS-CoV-2 transmission during rugby league matches: Do players become infected after participating with SARS-CoV-2 positive players?' (see page 807) and also an infographic on 'COVID-19 RT-PCR testing for elite athletes',(see page 818) which addresses how COVID-19 has directly affected elite sport.

'Department of Sport \& Exercise Medicine, Spire Tunbridge Wells Hospital, Spire Healthcare Ltd, Kent, UK ${ }^{2}$ Sports medicine physician, All England Lawn Tennis and Croquet Club Ltd, London, UK

${ }^{3}$ Secretary General, British Association of Sport and Exercise Medicine, Doncaster, UK

Correspondence to Dr Robin Chatterjee, British Association of Sport and Exercise Medicine, Doncaster DN9 3QS, UK; robinchatterjee1@yahoo.co.uk

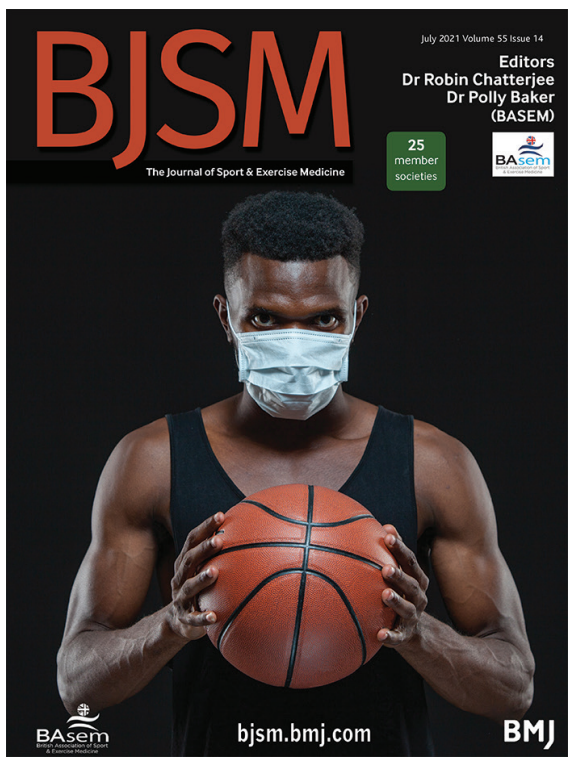

The original research studies, 'Injury patterns differ with age in male youth football: A four season prospective study of 1111 time loss injuries in an elite national academy'(see page 794) and 'Injury prevention knowledge beliefs and strategies in elite female footballers at the FIFA Women's World Cup France 2019'(see page 801), serve as a reminder that the physical and mental health issues that existed before the pandemic still remain. For the elite athlete, training during lockdown, having to live in bubbles and isolation from family and friends have added to the mental pressures, stresses and strains that already existed, such as those captured in the editorial 'Batting against mental health in elite cricket' (see page 765 ).

In the general population, although more people have been working from home than ever before, paradoxically the amount of physical activity some of these individuals have been doing appears to be less than before. This may be due to the closure of gyms and sports clubs during national lockdowns as well as increased working hours due to a blurring of lines of when the working day begins and ends, as well as mental health issues from not being able to see friends and family. In an attempt to maintain some semblance of physical fitness, individuals have taken to wearable technology more than ever before. These devices, such as smartwatches, are designed to collect the data of users' personal health and exercise. Individuals use these data to help regulate how much exercise they undertake and can provide them with achievable goals that can be incorporated into their daily lives. These devices can even send a user's health information to a doctor or other healthcare professional in real time. It is imperative that these devices are accurate and efficacious. This issue includes two consensus statements-'Recommendations for determining the validity of consumer wearable heart rate devices: Expert statement and checklist of the INTERLIVE Network' (see page 767) and 'Recommendations for determining the validity of consumer wearable and smartphone stepcount: Expert statement and checklist of the INTERLIVE Network' (see page 780) - that address this new form of physical activity adjunct. We also include an infographic that looks at behaviour change interventions to increase men's physical activity (see page 816).

To conclude, as the problems of our patients evolve with the changing times, while we will also change our educational focus, we will still maintain the highest standards of research and provide you with the tutelage you need to navigate the new normal.

\section{Twitter Robin Chatterjee @sportsdocrob}

Funding The authors have not declared a specific grant for this research from any funding agency in the public, commercial or not-for-profit sectors.

\section{Competing interests None declared.}

Provenance and peer review Commissioned; internally peer reviewed.

(c) Author(s) (or their employer(s)) 2021. No commercial re-use. See rights and permissions. Published by BMJ.

\section{D) Check for updates}

To cite Baker P, Chatterjee R. Br I Sports Med 2021;55:763.

\section{Accepted 12 April 2021}

Br J Sports Med 2021;55:763

doi:10.1136/bjsports-2021-104356

\section{ORCID iD}

Robin Chatterjee http://orcid.org/0000-0002-48583642 